International Journal of Mechanical Engineering and Technology (IJMET)

Volume 11, Issue 6, June 2020, pp. 29-36, Article ID: IJMET_11_06_004

Available online at https://iaeme.com/Home/issue/IJMET?Volume=11\&Issue=6

ISSN Print: 0976-6340 and ISSN Online: 0976-6359

DOI: https://doi.org/10.34218/IJMET.11.6.2020.004

(C) IAEME Publication

\title{
DEVELOPMENT OF MMC'S MECHANICAL CHARACTERIZATIONS AND SEM ANALYSIS OF AL7075 REINFORCED WITH 50NM SILICON CARBIDE PARTICLES
}

\author{
Anil Kumar S Kallimani \\ Assistant Professor \& Head, Department in Mechanical Engineering, \\ Government Engineering College Huvinahadagali, Karnataka, India \\ N Chikkanna \\ Professor \& Chairman, Department of Aerospace \& Propulsion Technology, \\ Visvesvaraya Institute of Advanced Technologies (VTU), Karnataka India
}

\section{Suresha P}

Assistant Professor, Mechanical Engineering Department, South East Asian College of Engineering and Technology, Bangalore, Karnataka, India

\section{Hareesha G}

Assistant Professor, Mechanical Engineering Department, Government Engineering College, Huvinahadagali, Karnataka, India

\begin{abstract}
Metal matrix composites of aluminum alloy reinforced with silicon carbide reinforcement are useful in aerospace, automobile and general engineering industries because of their favourable microstructure and mechanical behavior. In this work, Composites of aluminum alloy Al7075 and 50nm silicon carbide were fabricated by using stir casting. Further tests like, compression, tensile, hardness and SEM analysis were carried out. a significant improvement in material strength is observed in aluminum alloy Al7075 metal matrix composite as compared to the Al7075 alloy without silicon carbide addition. Cast base metal and its composites were found to fairly predominantly in brittle mode. The 50nm silicon carbide content varies $0 \%, 2 \%, 4 \%, 6 \%$ \&8\%wt.fractions. Comparison of mechanical properties microstructure studies are presented in this paper.
\end{abstract}

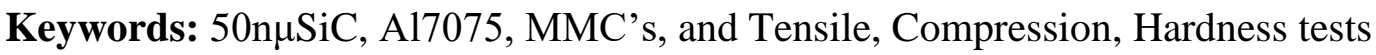
and microstructure studies 
Cite this Article: Anil Kumar S Kallimani, N Chikkanna, Suresha P and Hareesha G, Development of MMC's Mechanical Characterizations and SEM Analysis of Al7075 Reinforced with 50nm Silicon Carbide Particles. International Journal of Mechanical Engineering and Technology. 11(6), 2020, pp. 29-36. https://iaeme.com/Home/issue/IJMET?Volume=11\&Issue $=6$

\section{INTRODUCTION}

Metal matrix composites are obtained by popular aluminum alloy series such as $2000,3000,6000,7000$ etc which are used in aircraft structure design due to their high strength and weight ratio. due to the demand in high performance of the aircrafts weight reduction methods are used in aviation sector and new materials are under search.(1-5).Aluminum alloys reinforced with silicon carbide (MMC's) have shown greater signs in order to decrease the weight and consequently proved to be better structural components to provide strength to the structure. Vast research work has been undergoing in the area of MMC's. Because of their weight to strength ratio, MMC's are gradually replacing the popular Al.alloys which were used post world war in Aircraft and in other applications (8-16).

Present work describes the production of MMC's by using stir casting technique tensile, compression, hardness microstructure analysis of Al7075 Aluminum alloy with reinforcement of silicon carbide with various \%wt.

Table 1 Composition of the Al7075

\begin{tabular}{|l|c|c|c|}
\hline \multicolumn{1}{|c|}{ Element } & Wt.\% & Element & Wt\% \\
\hline Copper & 1.6 & Zinc & 5.5 \\
\hline Magnesium & 2.5 & Chromium & 0.15 \\
\hline Silicon & 0.4 & Titanium & 0.2 \\
\hline Iron & 0.5 & aluminum & Balance \\
\hline Manganese & 0.3 & & \\
\hline
\end{tabular}

The aluminum zinc alloy matrix is being chosen in this work as it is mostly used to make bulkheads and struts of undercarriage, engine mountings which carry concentrated heavy mass in an aircraft. The nanometric SiC powder (size 50nm) is used as a reinforcement with mentioned compositions. This composition was determined on a SPECTROMAX machine. The testing specimens with different wt.fractions were prepared using popular low cost stir casting method.

- For manufacturing of composite samples and their testing, Following machines and equipment's are used. Matrix (Al 7075 alloy) and 50n $\mu$ SiC Reinforcement (SiC)

- Weighing Machine

- Crucible (Graphite)

- Furnace

- Mould (Mild Steel)

- Stirrer

- Ultrasonic Probe (For ultrasonic stir casting

- Cutting Grinder

- Universal Testing Machine, Hardness and Lathe machines 


\section{DEVELOPMENT OF MMC'S BY USING STIR CASTING PROCESS}

The metal matrix composites are produced by using a stir casting process, crucible furnace molten metal poured in to graphite mold casted products as shown in below figure.

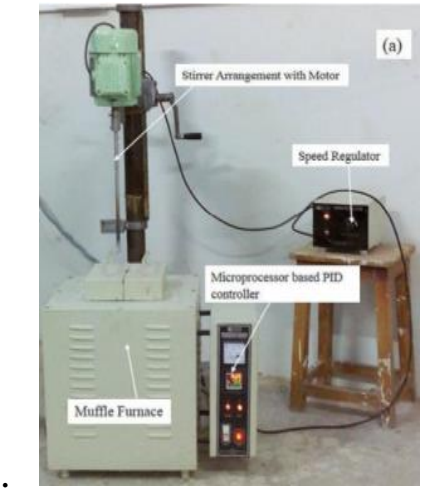

Figure 1 Stir casting set up

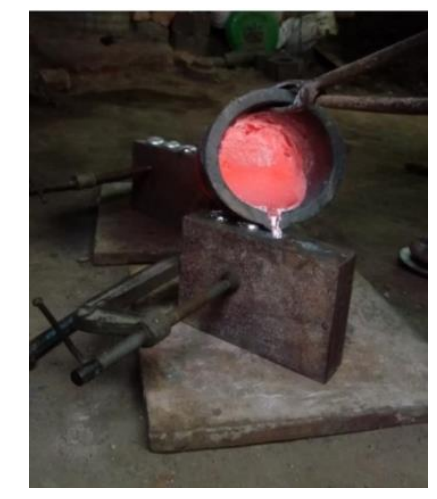

Figure 2 poured into mold

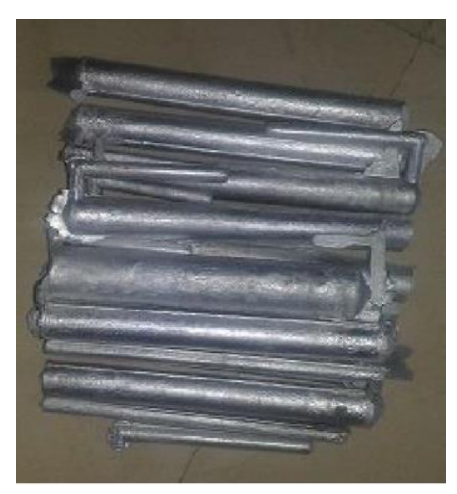

Figure 3 Casted products

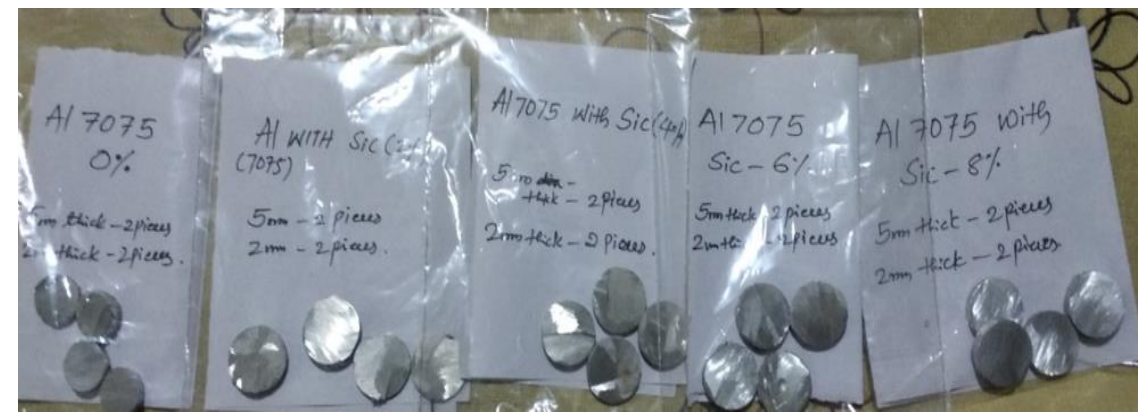

Figure 4 SEM samples

\section{EXPERIMENTAL DETAILS}

The base of metal matrix and the reinforcing phase for the present studies selected were Al7075 and particles SiC of size $50 \mu \mathrm{m}$. Table:1 Presented with the chemical composition of Al7075.

The commercial al-zn alloy blocks were heated at metling temperature with optimum care and standard procedure was followed to obtain the cast composites prepared by using the stir casting that shown in above fig:3.1. The particles were preheated before being introduced into the vortex and stirring of the molten composite were accomplished for 10 minutes at $400 \mathrm{rpm}$ stirrier speed. Pouring temperatures adopted were $477^{\circ} \mathrm{C}$. The moulds of $22 \mathrm{~mm}$ dia. X $210 \mathrm{~mm}$ length cast composites of A17075-SiC were obtained. Testing specimens were machined according to the ASTM Standards. Machined specimens of MMC's were undergone for Tensile, Compression, and Hardness tests. The samples of these MMC's were also checked for microstructure observations.

\section{RESULTS AND DISCUSSIONS}

\subsection{Production of MMC's}

Developed the metal matrix composites successfully by using the stir casting techniques as shown in fig: 1and casted products shown in fig 3.The reinforcement of SiC uniformly distributed in base metal of Al7075 and compositions are confirmed with using of SPECTROMAX testing machine. 
Development of MMC's Mechanical Characterizations and SEM Analysis of Al7075 Reinforced with 50nm Silicon Carbide Particles

\subsection{Tensile Test}

Tensile testing was being carried for Al7075 reinforced with nano SiC specimens as a function of percentage weight. The following results obtained for various combinations which are shown below table: 1 and variation of these values have been interpreted in the form of graphs in below fig: $5,6 \& 7$

Table 2 Tensile test properties

\begin{tabular}{|l|c|c|c|c|}
\hline Sl & Compositions & $\begin{array}{c}\text { UTS } \\
\text { (Mpa) }\end{array}$ & $\begin{array}{c}\text { YS } \\
\text { (Mpa) }\end{array}$ & \% Elangation \\
\hline 1 & $0 \% \mathrm{SiC}+\mathrm{Al} 7075$ & 213.15 & 174.49 & 14.29 \\
\hline 2 & $2 \% \mathrm{SiC}+\mathrm{Al} 7075$ & 227.36 & 181.32 & 14.10 \\
\hline 3 & $4 \% \mathrm{SiC}+\mathrm{Al} 7075$ & 252.89 & 199.89 & 13.2 \\
\hline 4 & $6 \% \mathrm{SiC}+\mathrm{Al} 7075$ & 299.62 & 234.62 & 12.6 \\
\hline 5 & $8 \% \mathrm{SiC}+\mathrm{Al} 7075$ & 359.69 & 259.69 & 11.10 \\
\hline
\end{tabular}

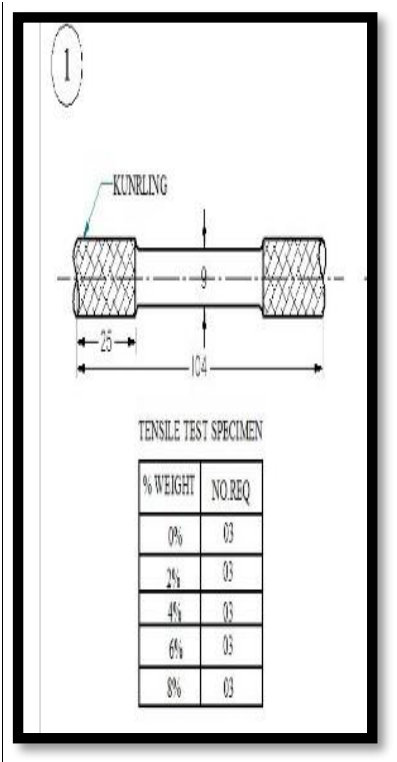

Figure 5 ASTM-E8

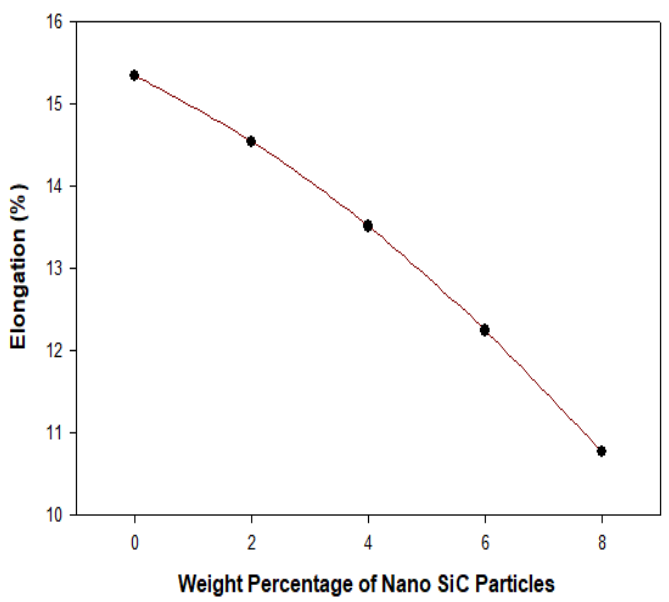

Figure 7 Percentage of Elongation

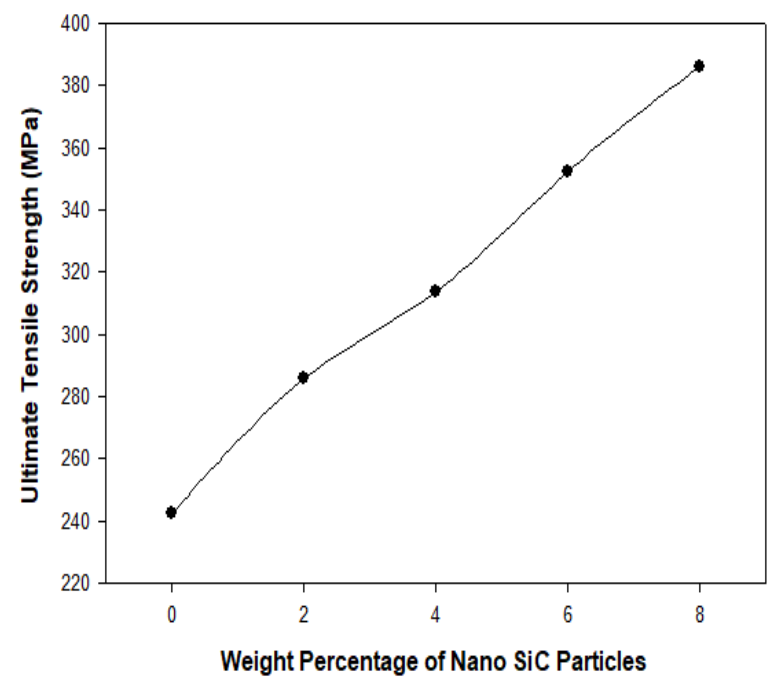

Figure 6 Ultimate tensile Strength

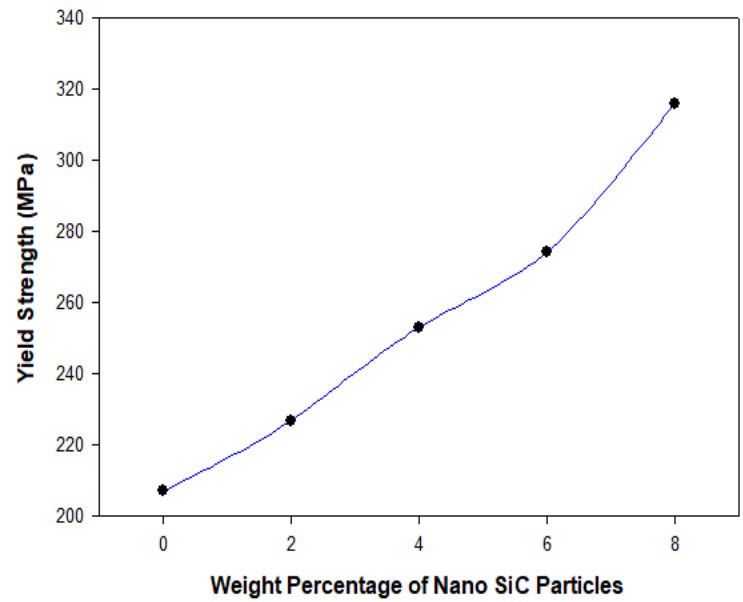

Figure 8 Yield Strength 
From figure $6 \& 7$ from the graphs, it is very much clear that tensile strength and yield strength have been gradually increased with the gradual increase in wt. Percentage of nano $\mathrm{SiC}$. It is also observed that percentage elongation of Al7075-SiC is decreasing with increase in the weight percentage of reinforcement. Which clearly indicates in the fig: 8

\subsection{Compression Test}

Table 3 Compression strength properties

\begin{tabular}{|c|l|c|}
\hline Sl & \multicolumn{1}{|c|}{ Compositions } & $\begin{array}{c}\text { Compression strength } \\
\text { (Mpa) }\end{array}$ \\
\hline 1 & $0 \% \mathrm{SiC}+\mathrm{Al} 7075$ & 631.28 \\
\hline 2 & $2 \% \mathrm{SiC}+\mathrm{Al} 7075$ & 659.15 \\
\hline 3 & $4 \% \mathrm{SiC}+\mathrm{Al} 7075$ & 715.82 \\
\hline 4 & $6 \% \mathrm{SiC}+\mathrm{Al} 7075$ & 768.33 \\
\hline 5 & $8 \% \mathrm{SiC}+\mathrm{A} 17075$ & 783.03 \\
\hline
\end{tabular}

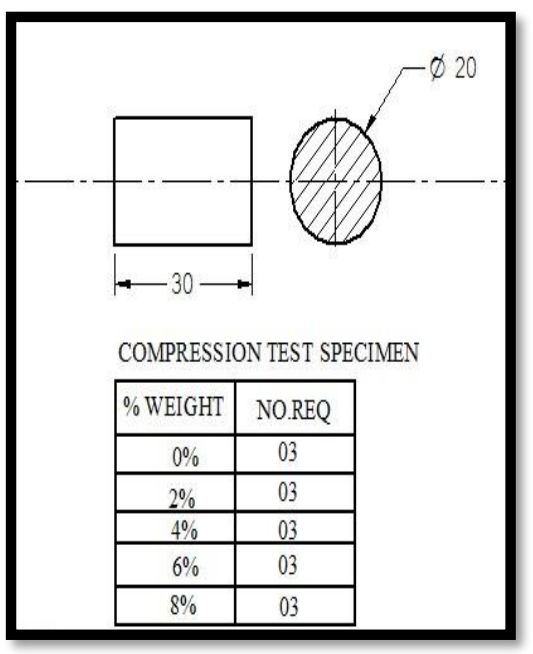

Figure 9 ASTM

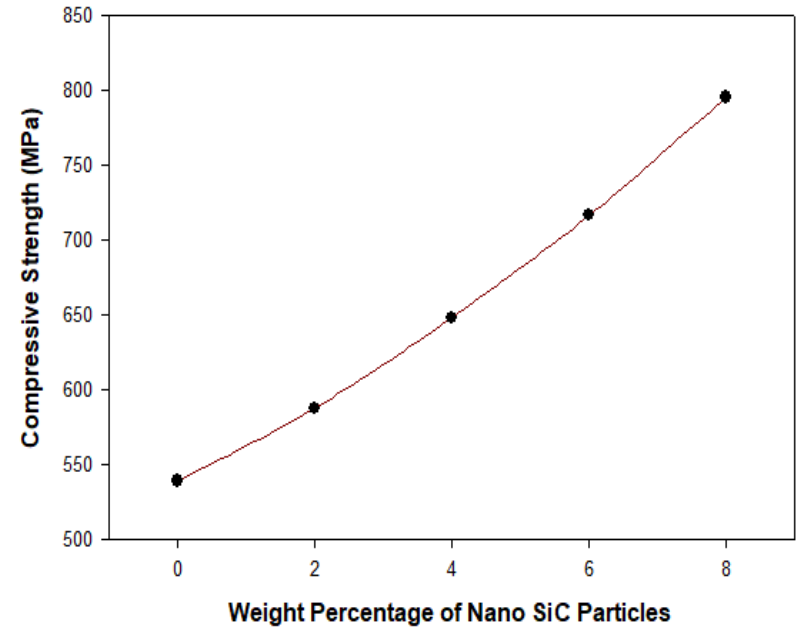

Figure 10 Compression strength

From the figure 10 Compression tests for the prepared specimen also revealed that compression strength of the specimen are higher than that of their base matrix. and have shown better increased compression strength values for the chosen wt.fractions of nano SiC. which will lead to improve the brittleness of MMC's.

\subsection{Hardness Test}

Table 4 BHN

\begin{tabular}{|c|l|c|}
\hline Sl & \multicolumn{1}{|c|}{ Compositions } & BHN \\
\hline 1 & $0 \% \mathrm{SiC}+\mathrm{Al} 7075$ & 66.60 \\
\hline 2 & $2 \% \mathrm{SiC}+\mathrm{Al} 7075$ & 74.30 \\
\hline 3 & $4 \% \mathrm{SiC}+\mathrm{Al} 7075$ & 82.17 \\
\hline 4 & $6 \% \mathrm{SiC}+\mathrm{Al} 7075$ & 99.40 \\
\hline 5 & $8 \% \mathrm{SiC}+\mathrm{Al} 7075$ & 110.60 \\
\hline
\end{tabular}



with 50nm Silicon Carbide Particles

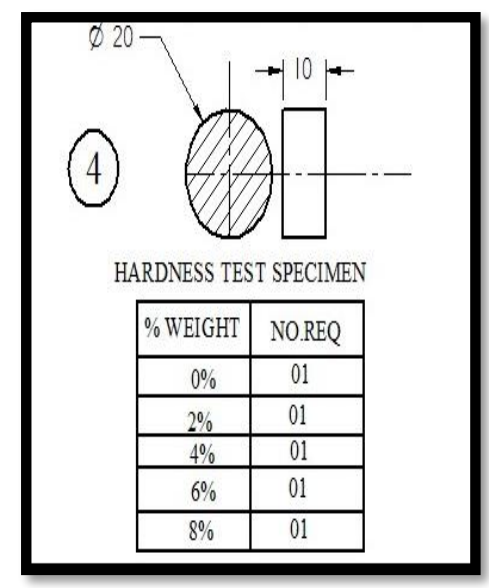

Figure 11 ASTM

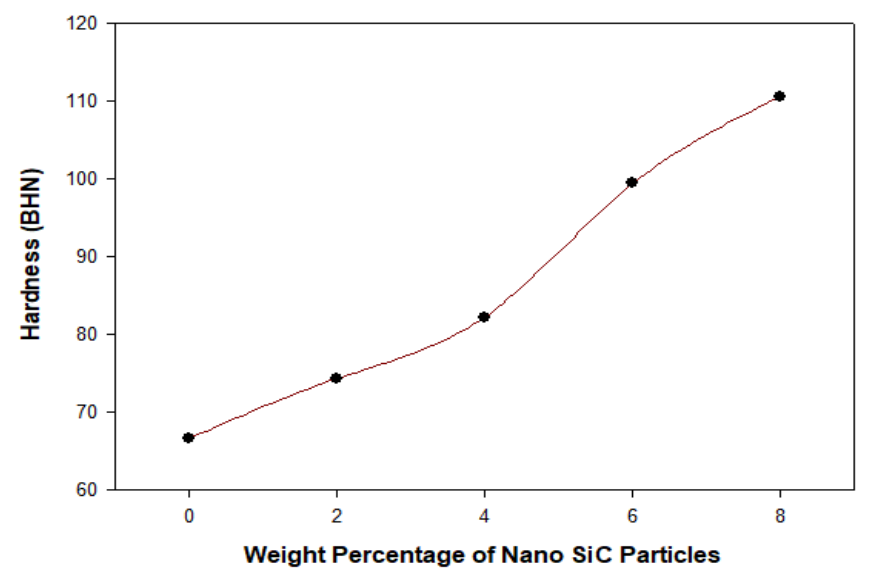

Figure $12 \mathrm{BHN}$ although heat treated

Al7075-T6 and Al7075-T651 alloys show good resistance to plastic deformation under predetermined loads, The nonmetric $\mathrm{SiC}$ reinforced specimens also were tested using indenter at an applied load of $100 \mathrm{~N}$ and are presented in figure 12 From the figure, it shows that higher values of hardness were obtained with increase in the amount of reinforced $\mathrm{SiC}$.

\subsection{Microstructure Studies using SEM}

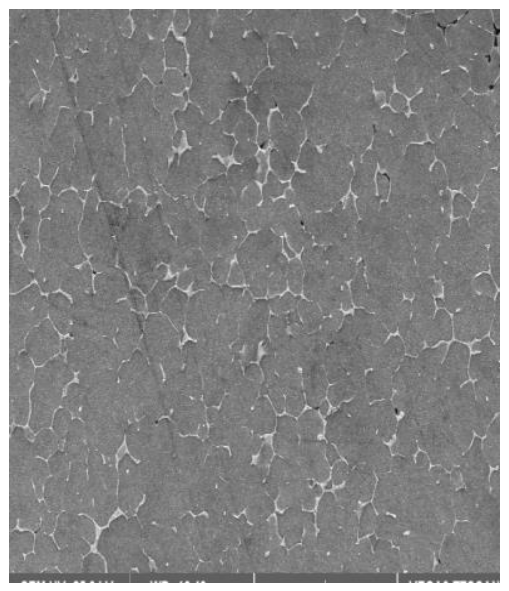

$\mathrm{Al} 7075+0 \% \mathrm{SiC}(\mathrm{a})$

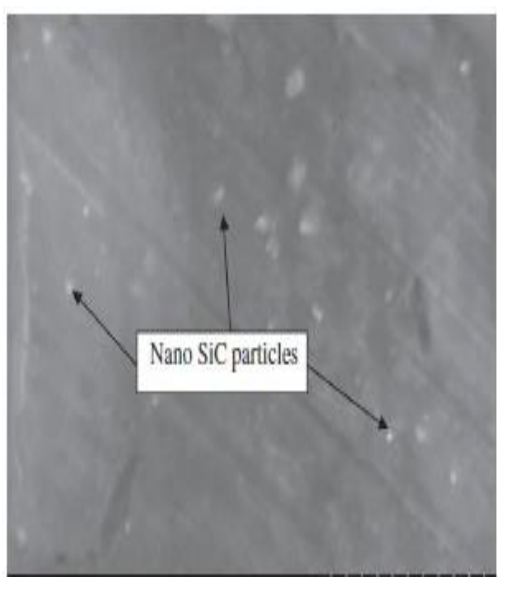

$\mathrm{Al} 7075+2 \% \mathrm{SiC}(\mathrm{b})$

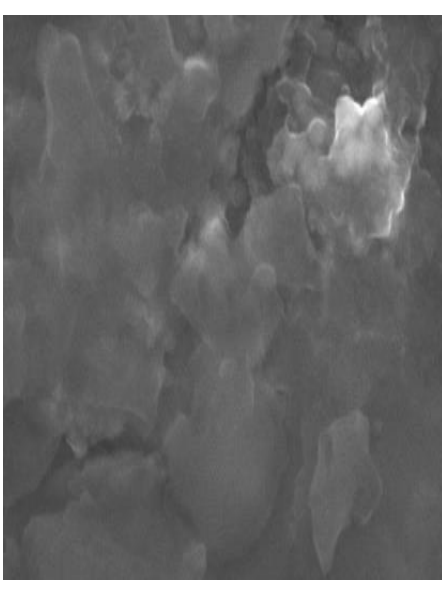

$\mathrm{Al} 7075+4 \% \mathrm{SiC}(\mathrm{c})$

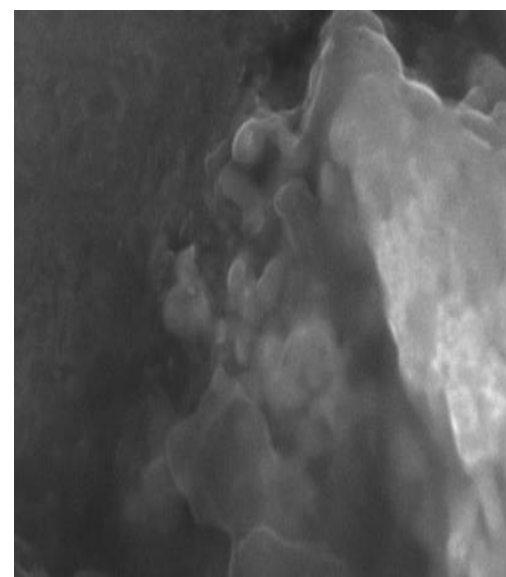

$\mathrm{A} 17075+6 \% \mathrm{SiC}(\mathrm{d})$

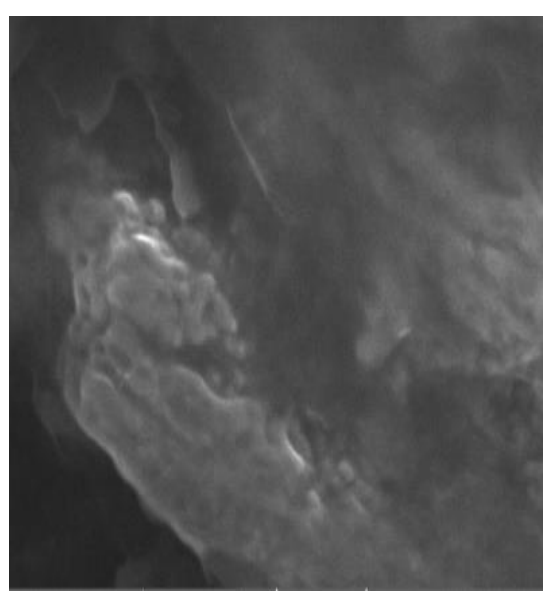

$\mathrm{Al} 7075+8 \% \mathrm{SiC}(\mathrm{e})$

Figure 13 SEM analysis of Al7075/SiC 
Figures: 13 (a-e) is presented with the microphotographs (SEM analysis) of cast Al7075nanoSiC samples respectively. Suitable sizes were taken from the prepared samples. These pieces are prepared carefully by polishing the surface using graded sequence of abrasive materials to get flat scratch free surface for the micro structural analysis. The distribution of reinforced $\mathrm{SiC}$ particles in Al7075 matrix with 0, 2, 4, 6, and 8 weight percentages was studied using scanning electron microscope. The above images shows silicon carbides of mesh 600 under magnification 1500x and the images reveal the uniform distribution of SiC particles in Matrix material.

\section{CONCLUSIONS}

The significant conclusions of the studies on Al7075-50 nm SiC metal matrix Composites are as follows.

1. Stir casted Al7075 reinforced with $\mathrm{SiC}$ were successfully adopted in the preparation of Al7075-SiC composites containing the filler contents from $0 \%$ to $8 \mathrm{wt} \%$ of SiC.

2. The microstructure topography of the reinforced matrix surface revealed the uniform distribution of the particles in the matrix system.

3. The tensile strength properties of the composites are found higher than that of base Al7075 alloy.

4. Improved compressive values obtained with increase in the weight percentage of SiC.

5. It was also observed that hardness value showed better improvement with higher BHN

6. Images of the samples taken from scanning electron microscope suggests uniform distribution of $\mathrm{SiC}$

7. From the studies in overall it can be concluded that A17075-SiC exhibits superior mechanical properties.

8. Improved results can be worked out by different fabrication methods and also by using different sizes of nano $\mathrm{SiC}$ patricles.

\section{REFERENCES}

[1] A.K.Kaw "Mechanics of Composite Materials" Taylor and Francis Group, Press 2006) LLC(CRC)

[2] Hasim, J., Looney, L., Hashmi, M. S. J. "Metal matrix composites production by the stir casting method", Journal of Materials Processing Technology (Elsevier 1999) Vol.9293,pp1-7.

[3] Vikram Singh and R.C. Prasad "Tensile and fracture behavior of Al 606-SiC metal matrix Composites"

[4] Sahin, Y "Preparation and some properties of SiC particle reinforced aluminium alloy composites" Materials and Design 24 (Elsevier 2003), 671-679.

[5] Davis, J.R (Ed.) "Properties and Selection, Nonferrous alloys and Special Purpose Materials", MetalsHandbook Vol 2 (ASM International1990), 592-633.

[6] W. Zhou , Z. M. Xu "Casting of SiC Reinforced Metal Matrix Composites" Journal of Materials Processing Technology 63 (Elsevier 1997)358-363

[7] B Agarwal and D. Dixit "Fabrication of aluminium based composites by foundry techniques", Transaction of Japan Institute of Metals Vol 22 (8) (1981)93.

[8] M. Mares "Some issues on tailoring possibilities for mechanical Properties of particulate reinforced Metal matrix Composites" Journal of Optoelectronics and Advanced Materials, Vol. 3(1) (2001),119- 124. 
Development of MMC's Mechanical Characterizations and SEM Analysis of A17075 Reinforced with 50nm Silicon Carbide Particles

[9] W.Clyne "Metal Matrix Composites: Matrices and Processing", Encyclopaedia of Materials: Science and Technology (Elsevier 2001).

[10] T.W.Clyne "Metal Matrix Composites: Matrices and Processing", Encyclopaedia of Materials: Science and Technology (Elsevier2001).

[11] T.W. Clyne and P.J. Withers. "An Introduction to Metal Matrix Composites" 1st Ed., Cambridge University Press, Cambridge, 1993. pp.1-10.

[12] D.M. Skibo, D.M. Schuster and L. Jolla. "Process for preparation of composite materials containing nonmetallic particles in a metallic matrix and composite materials "US Patent No. 4-786-467(1988)

[13] F. Khomamizadeh and A. Ghasemi "Evaluation of Quality Index of A-356 Aluminum Alloy by Microstructural Analysis, Scientia Iranica, Vol.11(4) (2004)386-391.

[14] Mohan Vanarotti, Shrishail P, B R.Sridhar, K.Venkateswarlu \& S A. Kori,"Study of Mechanical Properties \& Residual Stresses on Post Wear Samples of A356-SiC Metal Matrix Composites” Procedia Material Science, Vol 5 (Elsevier, 2014) 873- 882.

[15] George E Deiter “Mechanical Metallurgy" SI Metric Edition (McGraw-Hill1988)

[16] Sidney H Avner “ Introduction to Physical Metallurgy” (Tata McGraw Hill1997).

[17] N. Cayetano-Castro, H. J. Dorantes-Rosales, V. M. López- Hirata, J. J. Cruz- Rivera, J. Moreno-Palmerin, and J. L. González-Velázquez, "Coarsening kinetics of coherent precipitates in Fe-10\% Ni-15\% alloy," Revista de Metalurgia de Madrid, vol. 44 (2), (Elsevier 2008), pp. 162-169.

[18] K. Thornton, N. Akaiwa, and P. W. Voorhees, "Large-scale simulations of Ostwald ripening in elastically stressed solids: Development of microstructure" Acta Materialia, vol. 52 (5), (Elsevier 2004), pp.1365-1378

[19] M.Schober, C. Lerchbacher, E. Eidenberger, P. Staron, H. Clemens, and H.Leitner, "Precipitation behavior of intermetallic NiAl particles in Fe-6 at.\%Al-4at.\%Ni analyzed by SANS and 3DAP" Intermetallics, vol. 18 (8), (Elsevier 2010) pp. 1553-1559.

[20] N. Cayetano-Castro, M. L. Saucedo-Muñoz, H. J. Dorantes- Rosales, Jorge L. GonzalezVelazquez, J. D. Villegas-Cardenas, and V. M. Lopez-Hirata "Ostwald Ripening Process of Coherent $\beta \square$ Precipitates during Aging in Fe0.75Ni0.10 A 10.15 and Fe0.74 Ni0.10 $\mathrm{Al} 10.15 \mathrm{Cr} 0.0$ 